\title{
Conocimiento científico y problemas de salud. Una enfermedad emergente en Argentina, el Síndrome Urémico Hemolítico
}

| ${ }^{1}$ Marcela Beatriz Belardo |

Resumen: El artículo analiza la relación entre la producción de conocimiento científico y una enfermedad infantil llamada Síndrome Urémico Hemolítico. Nuestro objetivo es hacer hincapié en la forma en que la ciencia biomédica construye una forma de "mirar" y definir los problemas sociales, que en este caso es un problema de salud que afecta, principalmente en Argentina, a la población menor de cinco años de edad, y cómo a partir de esas características objetivas definidas por biomedicina, la salud pública, ha sostenido formas de abordar e intervenir en el asunto. A partir de una metodología cualitativa, la recolección de datos se llevó a cabo a través de un conjunto de técnicas que incluyó el análisis de fuentes secundarias tales como la revisión de los artículos científicos sobre la enfermedad, entrevistas semi-estructuradas con científicos y funcionarios públicos y la observación directa de los debates que se produjeron en distintas conferencias en torno a las propuestas de intervención para prevenir y controlar a la enfermedad. Se presentan las principales características por las cuales la biomedicina comprendió a la enfermedad para luego analizar las implicancias que tuvo en el diseño de políticas de salud. La planificación de políticas de salud siguió la lógica de la producción de conocimiento científico. Los nuevos descubrimientos que se fueron produciendo a lo largo del tiempo cambiarán casi de forma lineal el diseño de las políticas de prevención y control de la enfermedad.
1 Becaria Posdoctoral,

Conicet; Doctora en Ciencias Sociales UBA; Magíster en Epidemiología, Gestión y Políticas en Salud, UNLA; Docente universitaria UBA y UNLAM. Buenos Aires, Argentina. Correo electrónico: marcelabelardo@yahoo.com.ar
> Palavras-chave: conocimiento científico; paradigma epidemiológico; políticas de salud; Síndrome Urémico Hemolítico.
Recibido en: 22/05/2013 Aprobado en: 13/01/2014 


\section{Introducción}

El objetivo de este artículo es analizar la relación entre la producción de conocimiento científico y una enfermedad infantil emergente en Argentina denominada Síndrome Urémico Hemolítico (SUH). Nuestro interés está puesto en destacar cómo la ciencia construye una manera de "ver" y "definir" a los problemas sociales y cómo a partir de esas características objetivas que la ciencia biomédica define, se sustentan determinadas formas de abordar, intervenir y eventualmente brindar solución a los problemas.

El SUH es una enfermedad de transmisión alimentaria que afecta principalmente a niños menores de 5 años. Es definido como una entidad clínica caracterizada por anemia hemolítica microangiopática, plaquetopenia y grados variables de insuficiencia renal (EXENI, 2006). Con alrededor de 400-500 casos nuevos notificados por año, la enfermedad se ha convertido en un problema de salud pública en Argentina. De acuerdo con datos de la Sociedad Argentina de Pediatría (1995) el $60 \%$ de los niños que padecen SUH, se recupera sin secuelas. Sin embargo, a posteriori requieren de controles regulares porque muchos pueden desarrollar insuficiencia renal crónica como consecuencia tardía del síndrome, siendo el responsable del $20 \%$ de los trasplantes renales en niños y adolescentes (REPETTO, 1992; EXENI, 2001). La enfermedad no tiene un tratamiento específico. Desde su descubrimiento la diálisis peritoneal disminuyó la mortalidad, ubicándose alrededor de 3-4\% de los pacientes y con el transcurso del tiempo se ha demostrado que el tratamiento con antibióticos agrava el cuadro agudo de la enfermedad (WONG et al., 2000). En la última década, la incidencia anual estimada varió de 10 a 17 casos por 100.000 niños menores de 5 años (RIVAS, 2012). En Argentina no se han producido brotes de magnitud semejante a los de Estados Unidos (JUSKA et al., 2000), Canadá (ALI, 2004) o como más recientemente en Alemania donde pueblos enteros fueron afectados por la bacteria sino que la estadística nacional señala la aparición de numerosos casos de forma esporádica (RIVAS et al., 2006). Escherichia coli productor de toxina Shigal es responsable del SUH, siendo el serotipo ${ }^{2}$ O157:H7 el predominantemente aislado en Argentina (RIVAS et al., 2006). Las vías de transmisión de STEC que puede derivar en SUH son múltiples. La principal vía es la ingesta de alimentos contaminados como la carne picada y otros productos cárnicos crudos o insuficientemente cocidos, hamburguesas, embutidos 
fermentados, leche no pasteurizada, yogur, quesos y mayonesas (WORLD HEALTH ORGANIZATION 1997; RIVAS et al., 2003). No obstante, los alimentos no son la única vía de transmisión ya que se han comprobado contaminaciones asociados a la ingesta de agua no clorada, al uso de piletas de natación (CASTOR y BEACH, 2005) y la recreación en lagos contaminados (PÉREZ et al., 2000). También se demostró la transmisión persona-persona en investigaciones locales (RIVAS, 1996). Si bien los casos se producen durante todo el año, su frecuencia aumenta en la primavera, alcanzando un máximo en el verano y luego decrece en los meses más fríos (RIVAS et al., 2006).

La descripción clínica de casos de SUH se remonta a la década de 1960 con los primeros estudios del médico pediatra argentino Carlos A. Gianantonio (GIANANTONIO, 1964). Pero es recién en el año 2000 que la enfermedad ingresa a la nómina de Enfermedades de Notificación Obligatoria (ENO) y a partir de entonces se empiezan a implementar un conjunto de medidas sanitarias que confluyen en el 2009 en un Programa Nacional de control y prevención de la enfermedad.

A lo largo de la historia de la enfermedad tres actores fueron sumamente importantes a la hora de incorporar el tema a la agenda política de salud: la comunidad médico y científica especializada en la patología, los familiares de los pacientes organizados en ONGs y el rol jugado por los medios de comunicación que instalaron la temática por un período de tiempo más o menos prolongado dando visibilidad a nivel nacional de la existencia de la enfermedad. ${ }^{3}$ Podemos a su vez señalar que la historia de la enfermedad pasó por tres períodos. Un "período del descubrimiento" (1964-1981) que estuvo signado por los primeros contactos de la práctica médica con la enfermedad: las primeras descripciones de su expresión clínica, los ensayos con distintos tratamientos, y la formulación de diferentes hipótesis para dilucidar su etiología. Un segundo período denominado de la investigación (1982-1999) que estuvo fuertemente marcado por un descubrimiento a nivel internacional cuando se logra aislar por primera vez a la bacteria causante de la enfermedad. A partir de ese descubrimiento realizado por un equipo de científicos norteamericanos, se desarrolla en nuestro país un vasto conjunto de investigaciones sobre las características de las bacterias, las formas de transmisión y sus particularidades para el caso local, y estudios epidemiológicos de la enfermedad. Por último, un período que se denomina de 
las "primeras respuestas" (2000-2009) definido por el ingreso de la enfermedad a la nómina de ENO, la alianza entre los médicos y científicos y los familiares de los pacientes organizados en ONGs que movilizando recursos, estableciendo alianzas, teniendo presencia en los medios masivos de comunicación y promoviendo instancias formales intersectoriales de discusión sobre las mejores políticas de control y prevención para disminuir la incidencia de la enfermedad, ejercieron una presión a las autoridades de salud para que ingrese la temática a la agenda del Estado y se formulen políticas de salud que disminuyan la incidencia de la enfermedad en el país (BELARDO, 2012).

Este artículo analiza la constitución teórico-científica del SUH en Argentina. Nos interesa particularmente reconstruir la manera de "ver" y "definir" a la patología por parte de la ciencia biomédica en tanto esas características que le fueron atribuidas definieron el tipo de soluciones prácticas en materia de salud pública. La pregunta que subyace es ¿Cómo se fueron configurando los principales rasgos que definen a la patología y, por lo tanto, la manera de intervenir sobre la misma?

\section{Conocimiento científico y problemas sociales}

El artículo se enmarca en una investigación de mayor alcance cuyo propósito es comprender la construcción de políticas públicas, específicamente las políticas de salud. Partimos de la noción de que el diseño de una política entraña una manera de comprender y definir $y$, por lo tanto, de enfrentar un problema. Pero antes de cristalizarse en una política, entendida como conjunto de decisiones y de herramientas (técnicas, procedimientos, dispositivos) en los cuales la acción del Estado se materializa y operacionaliza, los problemas transitan por un camino, una suerte de "ciclo vital". Tienen una historia que comienza en un período concreto, sigue en los procesos que llevan a su surgimiento en tanto problema social y eventualmente concluyen con su resolución (OSZLAK, 1980). Desde esta perspectiva intentamos comprender cómo esta patología se fue incorporando a las distintas agendas (científica, social y política) y su interrelación a lo largo del ciclo hasta materializarse en una política de salud. Antes de que la enfermedad concitara la atención de los tomadores de decisiones en el ámbito político, la enfermedad acarreaba una "pre-historia", una historia relevante para la agenda de otros actores. La enfermedad se instala como un problema de conocimiento 
científico y como un problema social, cuestión que no sólo está fundada en hechos objetivos (por ejemplo, el número de casos anuales) sino también como resultado de procesos en los que diferentes actores escogen ciertos hechos, discuten sus significados y proponen prácticas de intervención sobre el problema. La producción de conocimiento científico participa en esa definición y hasta a veces en la imposición de determinados temas en la agenda social y los procesos de toma de decisiones políticas se fundamentan en una serie de abstracciones, argumentos y datos acerca de lo que es un "problema social". Estas abstracciones constituyen un relato "oficial" que se presenta como lineal y sin fisuras aparentes acerca de las características principales del problema, de las circunstancias que le dan origen y de las formas legítimas de intervenir sobre el mismo. Así, mediante intrincados procesos sociales de negociación simbólica y material, ciertas concepciones e intereses se objetivan en un conjunto de "hechos", en lo posible cuantificables, que aparecen como indiscutibles, reafirmando la objetividad del problema (KREIMER; ZABALA, 2007). La producción de conocimiento científico por parte de diferentes actores vinculados a la producción, promoción y divulgación del conocimiento se ha convertido en una estrategia legítima $-\mathrm{y}$ hegemónica- de intervención para dar respuesta a los problemas sociales.

Sólo desde la comprensión de esas trayectorias de las enfermedades es que las políticas que se formulan para dar soluciones adquieren sentido y pueden ser explicadas. Todos los actores sociales caracterizan inevitablemente a los problemas de determinada forma: enfatizan algunos aspectos y no otros; promueven orientaciones específicas; focalizan en determinadas causas y promueven soluciones particulares (BEST, 1995, p. 3-16.). Cómo está definido un problema social determina en gran medida las posibilidades que tendrá para que el sistema político lo considere digno de ser objeto de una nueva legislación o de una política pública y determina asimismo el abanico de respuestas posibles. En el caso de nuestro objeto de investigación, la producción de conocimiento científico nos proporcionó una manera de ver y definir a la enfermedad que luego tuvo implicancias en las soluciones prácticas en la formulación de políticas de salud que posteriormente confluyeron en un programa nacional de control y prevención de la enfermedad. De esta forma prestamos especial atención a la manera en cómo el conocimiento científico participó de las distintas instancias de intervención sobre el problema pero también a la forma en que los resultados que surgieron de 
las investigaciones científicas participaron en la propia definición del problema y cómo estas definiciones condicionaron las estrategias de intervención sobre la enfermedad, analizada en tanto objeto de política pública.

La construcción del SUH en tanto objeto científico no ha escapado al paradigma dominante de la epidemiología del riesgo. Sin embargo, nos interesa describir las características particulares que adoptó en esta enfermedad. Es necesario aclarar que no se cuentan con investigaciones desde el campo de las ciencias sociales en nuestro país que hayan analizado esta temática.

\section{Metodología}

Con un diseño exploratorio-descriptivo, que apunta a la reconstrucción de un proceso particular, la estrategia metodológica es cualitativa, sobre la base de fuentes secundarias y primarias. Los datos que utilizamos para la elaboración de este artículo provinieron de una lista de 37 artículos científicos nacionales provista por especialistas en el área. De esa lista se utilizaron para este artículo aquellos que abordan los aspectos epidemiológicos de la enfermedad. La información extraída de los artículos científicos fue verificada a lo largo del proceso de investigación con entrevistas semi-estructuradas realizadas tanto a científicos como a funcionarios de Estado. En este artículo se incluyeron dos entrevistas, una a la referente del área epidemiológica a nivel nacional y la otra al entonces Director Nacional de Alimentos. A su vez, se incorporaron las transcripciones de algunas exposiciones que se obtuvieron mediante la técnica de la observación directa en los congresos científicos y en distintos ámbitos con participación intersectorial que se constituyeron para formular planes en materia de intervención sanitaria.

La revisión, sistematización y análisis de los datos recolectados mediante estas tres técnicas se realizó con el objetivo de comprender los discursos que se construyeron a lo largo del tiempo, destacando aquellos aspectos que prevalecieron y el énfasis puesto sobre determinadas causas que fueron promoviendo determinadas maneras de intervenir sobre la enfermedad.

\section{Los modos de ver y definir al SUH de las ciencias biomédicas}

Como se señaló anteriormente, la enfermedad pasó por distintos períodos dentro del campo de las investigaciones biomédicas hasta finalmente configurarse como 
un problema social y que además concitó la atención de la agenda de la salud pública argentina. La investigación científica en parte puso en evidencia al SUH como un problema social y legitimó que la sociedad considere indispensable destinar una parte de los recursos para brindar soluciones prácticas. La ciencia biomédica fue construyendo a lo largo de 40 años un conjunto de definiciones, saberes y certezas sobre la enfermedad que enumeramos y analizamos a continuación.

En primer lugar, describimos la organización temática de sus investigaciones que va revelando la producción de conocimiento sobre la patología. Sus principales objetos cognitivos fueron inicialmente el cuerpo enfermo, posteriormente los estudios sobre la bacteria (agente causal), los reservorios y las vías de transmisión y en la actualidad el desarrollo de vacunas. En su gran mayoría, las investigaciones fueron financiadas por el Estado y tuvieron lugar en diversas entidades públicas como universidades nacionales, institutos dedicados al desarrollo nacional tecnológico agropecuario como el INTA, aquellos dedicados a las políticas científicas y técnicas vinculadas a distintos aspectos de acciones sanitarias en el ámbito público como la Administración Nacional de Laboratorios e Institutos de Salud (Anlis) "Dr. Carlos G. Malbrán” dependiente del Ministerio de Salud de la Nación, institutos dependientes del Consejo Nacional de Investigaciones Científicas y Técnicas (Conicet), hospitales de niños provinciales y nacionales, el Instituto Nacional de Enfermedades Infecciosas (INEI dependiente del ANLIS), y el Instituto Nacional de Tecnología Industrial (INTI). Esta realidad nos marca que, a diferencia de otras enfermedades también con una vasta producción científica, por ejemplo, el VIH/Sida, el SUH es uno de los pocos casos en Argentina en el que la agenda de investigación tanto básica como clínica ha sido una agenda básicamente de característica endógena desde el descubrimiento de la enfermedad en la década de los $60^{\prime}$. Es decir, ha sido una agenda que se ha constituido a partir de las inquietudes y necesidades propias del ámbito nacional y local. El SUH en tanto problema de conocimiento científico contribuyó a construir un discurso público acerca de las características principales de la enfermedad y las formas legitimas de intervenir así como una interpelación particular a la intervención del Estado que empezó a materializarse en 2001. A continuación describimos los rasgos principales que fueron configurando un relato "oficial" de la enfermedad, características objetivas que han sustentado formas de entender, abordar e intervenir sobre la problemática: 
a) El SUH es considerado una enfermedad emergente y por tal la Organización Panamericana de la Salud (OPS) desde el 2008 advierte sobre la necesidad de la investigación epidemiológica brindando apoyo a los Estados para que implementen sus recomendaciones;

b) En Argentina, el SUH es considerado una enfermedad endémica cuya tasa de incidencia es sensiblemente superior a la de otros países;

c) La bacteria causante es Escherichia coli productor de toxina Shiga;

d) La principal vía de transmisión es el consumo de carne bovina insuficientemente cocida, y como Argentina es el consumidor per cápita más importante del mundo, la peligrosidad del contagio en el país es mayor;

e) Se considera que la infección es causada fundamentalmente por los malos hábitos alimenticios de la población (falta de higiene, inadecuada cocción de carnes, problemas en la refrigeración de los alimentos, etc.).

Las características descritas conformaron un "relato" que se materializó en un conjunto de hechos que aparecen como indiscutibles, reafirmando la objetividad del problema y es a partir de estos hechos que se proponen maneras de intervenir desde la salud pública.

El enfoque predominante a partir del cual se explicó la enfermedad se centró en el denominado triángulo ecológico compuesto por un huésped (niños), un agente causal (bacteria) y el medio ambiente. Esta teoría vinculada al predominio del pensamiento clínico y epidemiológico estudió los problemas de salud y enfermedad de las poblaciones en sus manifestaciones individuales.

A pesar que algunos estudios sobre el SUH se explicaban desde el enfoque de la tríada ecológica (VOYER 1996, p. 197), las relaciones y dinámicas sociales no fueron su objeto de estudio. Se entendió al "medio ambiente" como una simple sucesión de indicadores externos o factores contextuales tales como condiciones socioeconómicas, zona de residencia o lugar del brote, que rodean al fenómeno, pero que no son determinantes de su producción.

A diferencia de otras enfermedades diarreicas asociadas principalmente a condiciones de pobreza y malnutrición, el SUH ha sido definido desde el discurso epidemiológico como una enfermedad que afecta principalmente a la población infantil de las clases media y alta. Esto, por otra parte, reproduce cierto prejuicio del sentido común científico que "lo social” afecta a los sectores más pobres y/o 
marginales, y que indagar en dinámicas sociales en los distintos sectores de la sociedad, aun en los sectores medios y los más privilegiados, no merece la pena.

El libro más completo que se ha escrito en la Argentina pertenece al médico Luis Voyer (1996), titulado Sindrome Urémico Hemolítico. En él se describe la historia natural de la enfermedad y sus características epidemiológicas principales. Analizamos en particular este estudio porque es el único en Argentina que relacionó la enfermedad con la clase social. Pero fundamentalmente tomamos sus conclusiones porque las afirmaciones del Dr. Voyer se transcriben en la mayoría de los estudios epidemiológicos posteriores a la publicación de su libro y sus conclusiones se repiten en todos los congresos científicos. En el capítulo 8 de su libro presenta las características de los enfermos: edad, sexo, estado nutritivo y clase social. Es interesante observar cómo llega a la conclusión de que mayoritariamente los niños afectados por SUH provienen de la "clase social media con buenas condiciones sanitarias y ambientales":

Basado en un viejo aforismo médico que dice que los virus eligen los mejores huéspedes es posible que el SUH generalmente no se dé en niños que proceden de ambientes con deficientes condiciones sanitarias por un problema de competencia bacteriana ya que estos niños padecen con frecuencia de infecciones intestinales por gérmenes que podrían impedir el desarrollo del ECVT (p.203).

A su vez, esta afirmación está respaldada en que:

La bacteria 0157:H7 no se aisló en aborígenes con diarrea y malas condiciones higiénicas en Australia, ni tampoco en niños de Tailandia, Corea, Brasil o la India (p. 204).

\section{Y agrega:}

La presentación de la enfermedad mayoritariamente en niños de clase media con buenas condiciones sanitarias y ambientales, también podría estar parcialmente condicionada por un mayor riesgo de infección por distintos hábitos alimentarios (p.204).

Voyer destaca los estudios realizados en Canadá que han referido mayor incidencia de SUH en los hijos de profesionales médicos y abogados, interpretándose que esto podría deberse a razones profesionales. Los hijos de médicos y abogados comen con mayor frecuencia en lugares de comidas rápidas debido a su vida agitada. Y señala:

Fue siempre notorio que entre los niños afectados predominan los de descendencia europea, de tez clara, a veces francamente rubios, siendo poco frecuente observar niños afectados de tez obscura descendientes de nativos americanos. Si bien esto puede estar relacionado en parte a las condiciones socioeconómicas, observaciones 
Aquí nos encontramos con dos argumentos que explican las características del universo afectado por la enfermedad. Por un lado, se afirma que el SUH es una enfermedad de las clases media y media-alta y esta afirmación se sustenta en la experiencia médica a través del contacto visual: tez clara, a veces francamente rubios siendo poco frecuente observar niños afectados de tez oscura. A su vez, este argumento se refuerza desde la evidencia científica que afirma no haber encontrado la bacteria 0157:H7 en aborígenes australianos, ni en niños de países pobres como Tailandia, Corea, Brasil o India. La otra cara de su análisis es el énfasis que dirigió hacia las características de los individuos con sus respectivas conductas y estilos de vida. Así se llega a la conclusión de que los hábitos alimenticios de determinadas ramas profesionales llevarían a un mayor riesgo de contacto con la bacteria.

Como señalamos anteriormente, es común escuchar en los congresos o leer en los artículos científicos la afirmación de que los niños que contraen SUH son niños eutróficos, por ende, provenientes de clases sociales media y alta y es inusual encontrar niños afectados por la enfermedad proveniente de la clase baja. Sin embargo, estas afirmaciones se sustentan en investigaciones realizadas en otros países con realidades muy diversas entre sí incluyendo a la Argentina. No existe razón fundada para transpolar esos datos y sus conclusiones a la realidad nacional. Sostener que no se ha encontrado la bacteria en aborígenes australianos, brasileños, tailandeses, coreanos o indios no significa que esos hallazgos puedan trasladarse a los niños argentinos. En el mismo sentido, tampoco se puede extender la conclusión de que todos los niños de tez blanca, caucásicos son el blanco de la bacteria a partir de la observación visual del médico de algunos casos.

Los datos que poseemos para la Argentina describen algunos rasgos de los enfermos como su edad, el género y la distribución geográfica de los casos. Pero no se han desarrollado líneas de investigación para obtener evidencia que nos permita hacer propias las conclusiones de los estudios internacionales para el caso doméstico. Sin embargo, sí hubo investigaciones que analizaron las relaciones entre la enfermedad y factores de riesgo presumiblemente asociadas a la misma. La afirmación de que la enfermedad se produce fundamentalmente por malos hábitos alimenticios de la población es una definición que marcó intervenciones 
en salud pública basadas en los cambios en los estilos de vida de los individuos.

El concepto clave -y sus recomendaciones- es el de "comportamientos de riesgo". Este concepto coloca su mirada ya no solo en el grupo de riesgo específico (niños menores de 5 años) sino que amplió la problemática a la familia estimulando una implicación activa de la prevención, sobre todo de los padres. Hablar de comportamientos de riesgo remite a determinada conducta individual que debe ser modificada para evitar una posible enfermedad. Como fuera señalado por Marcelo Urquía (2006) el apoyo a la teoría de los estilos de vida no es políticamente neutral. Este paradigma adolece de una concepción que integre las realidades históricas, geográficas, culturales y ambientales de las poblaciones como explicamos con más detalle en la siguiente sección.

\section{El "mal de las hamburguesas": conocimiento científico y políticas de salud}

En el 2001 el SUH alcanzó reconocimiento como problema social en Argentina a partir de un hecho que tomó relevancia pública en los medios masivos de comunicación. Ante varias denuncias de consumidores, se encuentra Escherichia coli $\mathrm{O} 157: \mathrm{H} 7$ en hamburguesas de pollo y carne vacuna expedidas por la cadena de comida rápida McDonald's. A partir de allí el SUH empieza a hacerse conocido como El Mal de las Hamburguesas o Enfermedad de las Hamburguesas, o simplemente se asoció la enfermedad a las "hamburguesas de McDonald's". En el 2003 un niño de siete años fallece luego de más de tres meses de internación. La acción pública que iniciaron sus familiares junto a otras familias también afectadas por la enfermedad motivó una causa judicial orientada a establecer la forma de contagio de sus hijos en locales de comidas rápidas, fundamentalmente en McDonald's, que derivó en una polémica batalla mediática entre los defensores y detractores de la mencionada cadena de comidas rápidas. A partir de ambos sucesos que trascendieron en los medios masivos de comunicación por un período de tiempo más o menos prolongado, la comunidad médica y científica junto con los familiares de niños afectados fundaron dos ONGs - LUSUH y CANI - que ayudaron a potenciar la visibilización del problema, movilizaron apoyos y recursos reclamando a los organismos del Estado la responsabilidad para que asuman una política integral de salud. ${ }^{4}$ Así el grupo de investigadores con un pie en el Estado y el otro en las organizaciones de la sociedad civil fue construyendo un 
consenso en torno a la urgencia de combatir la enfermedad y propuso diferentes iniciativas para enfrentarla. LUSUH organizó varias jornadas entre 2007 y 2009 que permitieron construir espacios de debate para comprometer a distintos actores y formular políticas de control y prevención de la enfermedad. La dinámica de estos encuentros estuvo dada por una combinación entre exposiciones científicoacadémicas, balances de gestión del sector privado de alimentos y del sector público (diferentes organismos estatales) y la discusión de propuestas.

A continuación se describen una serie de fundamentos que hemos recolectado a través de la observación directa en todas estas jornadas y las entrevistas que realizamos a algunos científicos y funcionarios del Estado nacional. Se describen los argumentos de mayor peso que influyeron a la hora de abordar este tema como un problema para la salud pública.

Todos los discursos parten de la concepción de que esta enfermedad no puede ser erradicada sino mitigada, o sea, disminuir el número de casos que se producen anualmente. Su argumento principal es el impacto personal y social que genera en la población afectada, fundamentalmente en lo que refiere a los altos costos económicos que acarrea la enfermedad en las etapas aguda y crónica tanto para el sistema de salud como para el gasto de bolsillo directo de los pacientes. Este argumento está respaldado por un estudio sobre los costos directos e indirectos del tratamiento en todas las etapas evolutivas realizado en un importante Hospital de Niños y que fuera financiado por el Ministerio de Salud de la Nación (CALETTI, 2006). Otro argumento que relevamos es aquel que relaciona el número de casos anuales en el país con el número de casos que se reportan en otros países. Es decir, si bien el número de casos de SUH en relación a otras enfermedades no es tan elevado (400-500 nuevos casos por año) en relación a otros países es el país con mayor incidencia en términos comparados. ${ }^{5}$ Un tercer argumento explicativo del anterior refiere a que la enorme cantidad de casos que existen en Argentina "puede deberse al alto consumo de carne vacuna que tradicionalmente tiene la población" (entrevista personal, Director Nacional de Alimentos INAL). Sin duda estos hechos construidos a partir de evidencia científica reafirman la objetividad del problema por lo que organismos internacionales como la Organización Panamericana de la Salud (OPS) considere al SUH como enfermedad emergente y que por tal apoya a los Estados en la implementación de la investigación epidemiológica -fundamentalmente la 
investigación molecular- y que suscriba convenios con el Estado nacional para diseñar programas de prevención. ${ }^{6}$ La influencia de organismos internacionales reafirma la importancia en la intervención sobre el problema.

En otras palabras, la notificación obligatoria de la enfermedad a partir del 2000 produjo aún mayores certezas a la hora de considerar la importancia del síndrome autóctono a la vez que permitió comparar esos datos con la casuística mundial; la determinación de los costos económicos que acarrea la enfermedad tanto para los servicios de salud como para las familias reforzó la relevancia de la implementación de políticas de prevención y la decisión de organismos internacionales de investigar el tema brindó ciertas facilidades para la investigación local -aunque la misma se venía desarrollando con mucho esfuerzo desde hacía más de 30 años-.

A partir de estos fundamentos describimos las propuestas para disminuir la incidencia del síndrome. Anteriormente señalamos que las alternativas de intervención estaban basadas en los cambios comportamentales de la población. La relación entre determinados factores de riesgo y la probable producción de enfermedad como los malos hábitos alimenticios y de higiene devinieron en propuestas que pusieron la carga de la responsabilidad en los individuos. Una de las expertas en el tema señalaba en una de las entrevistas que la enfermedad se adquiere no sólo por un alto consumo de carne vacuna sino por la modalidad de su consumo: comer carne cruda o "jugosa”, chupar pedacitos de carne o tomar su jugo son prácticas habituales que se le enseña al niño y todo el universo de esas prácticas implica un alto riesgo asociados al componente de la carne (entrevista personal, Jefa del Servicio Fisiopatogenia del ANLIS, Laboratorio Nacional de Referencia para SUH y diarreas sanguinolentas). Justamente uno de los hábitos más resistentes a los cambios es precisamente la alimentación porque la gente come en función de lo biológico, lo ecológico-demográfico, lo tecnológico-económico, lo social y lo simbólico. Es decir, no es un hecho ni exclusivamente biológico ni totalmente social, une lo biológico y lo cultural de una manera tan indisoluble que difícilmente podamos separarlos y esto arranca de las características mismas de la especie humana (AGUIRRE, 2001). Pero a su vez, a lo largo de los años otros estudios epidemiológicos completaron el amplio abanico de las vías de transmisión y así demostraron la transmisión persona-persona por la ruta fecalorla, la contaminación cruzada de alimentos, el contacto directo del hombre con los animales y las aguas de consumo o de recreación contaminadas. A medida 
que la ciencia iba confirmando un conjunto de factores de riesgo asociados a la enfermedad también se fueron complejizando las propuestas de intervención en materia de salud pública y ese discurso permeó en otros actores no ligados al campo científico. En el discurso de inauguración de la I Jornada sobre SUH realizado en el 2008, el entonces Ministro de Salud de la Provincia de Buenos Aires manifestó que la bacteria "está en todos lados" y que había que "hacer algo" pero que no sabía si ese era el espacio y momento para concretarlo.

En las sucesivas jornadas de debate que presenciamos se llegaron a un conjunto de conclusiones que posteriormente formaron parte de un Programa Nacional de control y prevención de la enfermedad. El "menú" de propuestas de políticas de salud fue complejizándose con el tiempo. Si bien en un principio la modificación de los hábitos de las personas estaba a la orden del día, se sumaron otras medidas plausibles de ser implementadas con la rectoría del Estado como primer responsable por la salud de la población. Las propuestas entonces comprendieron: la modificación de los hábitos alimenticios e higiénicos de la población a través de campañas masivas de información sostenidas en el tiempo y la incorporación del tema en la currícula escolar del grupo mayormente afectado (escuela inicial y primaria) debido a que los niños son eficaces transmisores de información en el hogar; un conjunto de medidas correctivas a los largo de la industria y comercialización de la cadena alimentaria (lo que se denomina como del "campo al plato"); el estricto control con análisis clínicos para el reingreso de personas afectadas en instituciones cerradas (jardines de infantes, geriátricos o población carcelaria) y, por último, el apoyo psicológico a los familiares de los pacientes en el momento de la hospitalización.

Estas ideas fluctuaron en distintas "comunidades", involucrando a los especialistas en los distintos aspectos de la enfermedad, los planificadores de políticas públicas, los representantes ligados a la industria y comercialización de la carne vacuna y los miembros de las ONGs. Así en los últimos años el discurso pasó de preguntarse sobre la peligrosidad de las bacterias a preguntarse si la oferta de carne del país era segura. El discurso científico que durante las primeras décadas estuvo centrado en el cuerpo (en términos individuales) pasó a un discurso epidemiológico centrado en el cuerpo social (cómo impacta la enfermedad en la población y qué intervenciones adoptar desde los organismos estatales de control y prevención). Este último discurso aborda una dimensión 
"mas social", es decir, da cuenta de procesos que suceden a nivel macro como, por ejemplo, cuestionar el modelo de producción de alimentos en Argentina y poner en discusión los mecanismos de control de calidad de los alimentos y los responsables de su cumplimiento.

\section{Consideraciones finales}

El artículo analizó la constitución teórico-científica del SUH en Argentina. Particularmente reconstruimos la manera de ver y definir a la patología por parte de la ciencia biomédica. Se describieron los rasgos principales que fueron configurando un relato "oficial" de la enfermedad, características objetivas que sustentaron formas de abordar e intervenir sobre el problema desde la salud pública.

Con casi medio siglo de producción de conocimiento, la comunidad científica logra instalar a la enfermedad como un problema de salud e intervino a su vez en el diseño de políticas de salud. Ahora bien, comúnmente se considera que los problemas sociales vienen dados, están “ahí, en la vida real” y los científicos simplemente toman el problema en sus manos para buscar y brindar una solución. Sin embargo, también puede ocurrir el proceso inverso. La producción de conocimiento científico no es solamente un recurso orientado a la resolución de problemas sociales sino que puede cumplir un papel en los procesos de construcción de esos problemas (KREIMER; ZABALA, 2007).

En nuestro caso, durante décadas la enfermedad permaneció como un problema exclusivo de conocimiento médico-científico y fue ese mismo ámbito que contribuyó a construir a la enfermedad como un problema social y como un problema para la salud pública en Argentina. El SUH fue definido como una enfermedad emergente, endémica, con una tasa de incidencia superior a la de cualquier otro país, causada por una bacteria que se transmite fundamentalmente por "estilos de vida" no saludables, particularmente, los relacionados a malos hábitos alimenticios e higiénicos.

A partir de estudios epidemiológicos basados en factores de riesgos, el concepto clave que emerge es el de "comportamientos riesgosos" familiares. Entender a la enfermedad desde el paradigma de riesgo reforzó en el ámbito de la salud pública la implementación de campañas que fundamentalmente apuntaron a "corregir" hábitos malsanos, cargando así la mayor responsabilidad a las familias para evitar que sus hijos contraigan la enfermedad. En general, las propuestas de 
intervención emanadas linealmente de este tipo de estudios - y no solo en nuestro caso de estudio - subordina otros factores ligados a la esfera social y cultural desconociendo que existen hábitos arraigados que forman parte del modo de vida de las poblaciones y que son difíciles de modificar en términos individuales.

Sin embargo, también encontramos que a lo largo del tiempo el "menú" de propuestas fue ampliándose a otros campos que iban más allá de las prácticas de prevención en el ámbito familiar en la medida que se conocían nuevas investigaciones. La planificación política siguió la lógica de la producción de conocimiento científico; cuando la ciencia constituye entonces este relato no solo describe hechos objetivos sino que también discute y formula caminos de intervención para solucionar los problemas. Aunque consideramos que muchos de esos conocimientos no pueden trasladarse mecánica o linealmente en una práctica concreta de intervención en materia de salud pública.

\section{Referencias}

AGUIRRE, P. Del Gramillón al Aspartamo. Las transiciones Alimentarias en el tiempo de la especie. Boletin Techint, Buenos Aires, n. 306, abril-junio, 2001.

ALI, H.S. A socio-ecological autopsy of the E. Coli 0157:H7 outbreak in Walkerton, Ontario, Canada, Rev. Social Science \& Medicine, v. 58, p. 2601-2612, 2004.

BELARDO, M. Etapas históricas del Síndrome Urémico Hemolítico en Argentina (19642009). Arch Argent Pediatr., v. 5, n. 110, p. 416-420, 2012.

BEST, J. Images of issues. Typifying contemporary social problems. New Jersey: Transaction, 1995.

CALETTI, M.G. et al. A. Evaluación de costos directos e indirectos del tratamiento del Síndrome Urémico Hemolítico en sus distintas etapas evolutivas. Medicina. Buenos Aires, v. 66, supl 3, p. 22-26, 2006.

CASTOR, M.L.; BEACH, M.J. Transmisión de enfermedades asociadas a la recreación acuática. Estrategias para su disminución. Natación y diarrea, una nueva problemática de la salud pública. Correo de la SAP, v. 37, p. 1154, 2005.

EXENI, R. Síndrome Urémico Hemolítico. Archivos Latinoamericanos de Nefrología Pediátrica, v. 1, p. 35-56, 2001.

EXENI, R. Síndrome Urémico Hemolítico. Manifestaciones clínicas. Tratamiento. Medicina, Buenos Aires, v. 66, supl 3, p. 6-10, 2006.

GIANANTONIO, C.A. et al. The hemolytic uremic syndrome. J Pediatr, v. 4, p. 478491, 1964. 
JUSKA, A. et al. Manufacturing bacteriological contamination outbreaks in industrialized meat production systems: The case of E. coli 0157:H7. Rev. Agricultural and Human Values, v. 20, p. 3-19, 2003.

KREIMER, P.; ZABALA J. Producción de conocimientos científicos y problemas sociales en países en desarrollo. Rev. Nómadas, p. 110-122, 2007.

OSZLAK, O. Políticas Públicas y Regímenes Políticos: Reflexiones a partir de algunas experiencias Latinoamericanas. Documento de Estudios CEDES, Buenos Aires, v. 3, n. 2, 1980.

PEREZ GUZZI, J.I. et al. Isolation of Escherichia coli O157:H7 in storm drains in the city of Mar del Plata with bacterial contamination of fecal origin. Rev. Argent. Microbiol., v. 32, p. $161-164,2000$.

REPETTO, H.A. Follow up of hemolytic uremic syndrome in Argentina. En: Kaplan B.S.; Trompeter R.S.; MOAKE J.L. (Ed) Hemolytic uremic syndrome and thrombotic thrombocytopenic púrpura. New York: Marcel Dekker, 1992. p. 453-456.

RIVAS, M. Vigilancia epidemiológica y molecular del SUH asociado a Escherichia coli productor de toxina Shiga. En: 50 CONGRESO ARGENTINO DE NEFROLOGÍA PEDIÁTRICA y $3^{\circ}$ JORNADAS DE ENFERMERÍA Y DE TÉCNICOS EN NEFROLOGÍA PEDIÁTRICA, 21-23 junio, 2012.

RIVAS, M. et al. Home-prepared hamburger and sporadic hemolytic uremic syndrome, Argentina. Emerg. Infect. Dis. v. 9, p. 1184-1186, 2003.

RIVAS, M. et al. The epidemiology of hemolytic uremic syndrome in Argentina. Diagnosis of the etiologic agent, reservoirs and routes of transmission. Medicina. Buenos Aires, v. 66, supl 3, p. 27-32, 2006.

RIVAS, M. et al. Verocytotoxin-producing Escherichia coli infection in family members of children with Hemolytic Uremic Syndrome. Medicina. Buenos Aires, v. 53, p. 487-490, 1996.

SOCIEDAD ARGENTINA DE PEDIATRIA. COMITÉ DE NEFROLOGÍA. Incidencia del Síndrome Urémico Hemolítico (SUH) en la República Argentina. Arch. Arg. Pediatr, v. 93, p. 409-11, 1995.

URQUÍA, M.L. Teorías dominantes y alternativas en epidemiología. Buenos Aires: UNLA, 2006. VOYER L.E. Sindrome Urémico Hemolítico. Buenos Aires: López, 1996.

WONG, C.S.; JELACIC, S.; HABEEB, R.L. The risk of the hemolytic-uremic syndrome after antibiotic treatment of Escherichia coli O157:H7 infections. New Engl J Med., v. 342, p. 1930-1936, 2000.

WORLD HEALTH ORGANIZATION. Consultation on prevention and control of enterohemorrhagic (EHEC) infections. En: WHO proceedings of the report of a Who Consultation, Geneva, Switzerland, 1997. 


\section{Notas}

${ }^{1}$ Cuya sigla es STEC, de la expresión en inglés.

${ }^{2}$ Un serotipo es un tipo de microorganismo infeccioso clasificado según los antígenos que se presentan en su superficie celular (Nester y col. Microbiología Humana. Manual moderno, 2007).

${ }^{3}$ Para un estudio sobre la enfermedad en la prensa gráfica ver Belardo M. Enfermedad transmitida por alimentos. El Síndrome Urémico Hemolítico y su inclusión en las agendas biomédica, social y polític. En: Petracci, M.; Waisbord, S. (Comp.) Comunicación y salud en la argentina, La Crujía, Buenos Aires, 2011

${ }^{4}$ En el 2005 se funda LUSUH, la primera asociación civil sin fines de lucro. En el 2007 se crea la Fundación CANI por una Cultura Alimentaria para una Nutrición Inteligente, responsable y segura de la mano de una reconocida periodista argentina luego de que su hijo contrajera la enfermedad.

${ }^{5}$ En el 2000 la resolución No 346 del Ministerio de Salud estableció la notificación obligatoria del SUH al Sistema Nacional de Vigilancia Epidemiológica (SI.Na.V.E.) mientras que paralelamente se mantuvo la encuesta anual que ya venía realizándose a cargo de la Sociedad Argentina de Pediatría y el Instituto ANLIS-Malbrán a aquellos hospitales, públicos y privados, para monitorear el número de casos.

${ }^{6}$ El Ministerio de Salud suscribió un convenio con la OPS donde las partes acordaban implementar programas de prevención y control de enfermedades transmisibles, entre las que se encuentra el Síndrome Urémico Hemolítico. En la misma resolución (no 1062/08) se fundamenta la incorporación del SUH debido a que Argentina aparece como el país de mayor incidencia en el mundo. 
Conhecimento cientifico e problemas de saúde. Uma doença emergente na Argentina, a sindrome hemolitico-urêmica

$\mathrm{O}$ artigo analisa a relação entre a produção do conhecimento científico e uma doença infantil chamada síndrome hemolítico-urêmica. Nosso objetivo é enfatizar a forma em que a ciência biomédica constrói uma maneira de "olhar" e definir os problemas sociais, que neste caso é um problema da saúde que afeta, principalmente na Argentina, a população com menos de cinco anos de idade, e como a partir destas características objetivas definidas pela biomedicina a saúde pública sustentou formas de abordar e intervir sobre o assunto. A partir de uma metodologia qualitativa, o levantamento de dados foi realizado através de um conjunto de técnicas que incluiu a análise de fontes secundárias como a revisão de artigos científicos sobre a doença, entrevistas semiestruturadas com cientistas e funcionários públicos a observação direta dos debates em conferências sobre as propostas de intervenção para controlar e prevenir a doença. Apresentam-se as principais características a biomedicina na compreensão da doença e em seguida analisa-se sua implicação no desenho de políticas de saúde. A política de planejamento seguiu a lógica da produção do conhecimento científico. Novas descobertas foram ocorrendo ao longo do tempo e mudaram quase linearmente o desenho de políticas, de modo a prevenir e controlar a doença.

> Key words: conhecimento científico; paradigma epidemiológico; políticas de saúde; síndrome hemolíticourêmica. 
Scientific knowledge and health problems. An emerging disease in Argentina, the hemolytic uremic syndrome

The article analyzes the relationship between the production of scientific knowledge and a childhood disease named Hemolytic Uremic Syndrome. Our focus is on highlighting how biomedical science builds a way to "see" and define social problems, in this case a health problem that mainly affects the population under five years old in Argentina, and how from of those objective characteristics defined by biomedicine, public health sustained ways to address and intervene on the issue. From a qualitative methodology, data collection was conducted by a joint techniques included analysis of secondary sources, from the review of scientific articles on the disease, semi-structured interviews to scientists and public officials and observation at scientific conferences. We present the main features biomedicine concerning the disease and then analyze its implications on the design of health policies. Planning policy followed the logic of scientific knowledge production. New discoveries have been occurring over time and moved almost linearly to the design of policies to prevent and control the disease.

Key words: scientific knowledge; epidemiological paradigm; health policies; hemolytic uremic syndrome. 